\title{
Memória informacional da cultura no contexto da metalinguagem crítica de Lótman
}

\section{Informational memory of culture in the context of Lotman's critical metalanguage}

Irene de Araújo Machado

Professora Livre-Docente do PPG em Meios e Processos Audiovisuais, USP. Pesquisadora CNPq-PQ 1D. <irenemac@uol.com.br>

\section{RESUMO}

Estudo de caráter analítico-comparativo em que a metalinguagem crítica proposta por Lótman é focalizada a partir da abordagem tipológica da cultura e seus modelos espaciais topológicos. Nela a memória figura como dispositivo dotado de inteligência capaz de auto-regulação graças ao trabalho dos códigos em suas hierarquias complexas e de operações de corte sincrônico, favorável à relativização das escalas distintivas do passado e do tempo que leva ao esquecimento. Toma-se como objeto de análise experimental o documentário Nostalgia da luz, de Patricio Guzmán.

Palavras-chave: Metalinguagem crítica. Tipologia da cultura. Documentário.

\begin{abstract}
Analytical and comparative study in which Lotman's critical mentalinguistic approach is focused from the typological perspective of culture and the topological spatial models. Memory is taken as intelligent device equipped with the capacity of self-regulation thanks to the work of the codes in their complex hierarchies and synchronic operations, in favor of the relativity of the distinctive scales of the past and the time it takes to oblivion. It takes as the object of experimental analysis the documentary Patricio Guzmán's film Nostalgia for the Light.
\end{abstract}

Keywords: Critical Metalanguage. Tipology of culture. Documentary film.

\section{Apresentação do problema}

Em exercícios de análise comparativa a submissão dos termos envolvidos ao processo cognitivo nem sempre resulta em equiparações, sobretudo quando o processo considera sistemas culturais. Nesse caso específico, a comparação, desafortunadamente, tendea ressaltar a prevalência de uma cultura sobre outras. Hierarquias são criadas para firmar superioridades. Assim as culturas alfabéticas desenvolvidas no ocidente adquiriram a condição de excelência em detrimento de todas as demais culturas. Em raciocínios que tais, as culturas ágrafas ocupam o polo inferir o que permite atribuir ao nicho da cultura alfabética ocidental a escalada da civilização a partir da qual outras hierarquias emergem. Povos bárbaros, culturas primitivas e povos pré-colombianos engrossam as fileiras do patamar inferior do quadro tipológico formador da base sobre a qual se erguem 
grandes dicotomias: civilização vs. barbárie, nativo vs. estrangeiro, culto vs. inculto, cultura vs. não cultura.

Não é apenas o exacerbado grau de generalidade de tal raciocínio que reivindica urgência de reflexões sobre a insuficiência de tais dicotomias, mas, sobretudo, os efeitos nocivos de sua prática, explicitamente visíveis em todos os confrontos que mobilizaram e mobilizam embates políticos nacionais, internacionais, étnicos, ideológicos e religiosos que as disputas geopolíticas não deixaram passar desapercebidas no desenrolar dos séculos. Evidentemente, não poderia ficar imune à reflexão dos estudos da semiótica da cultura que se desenvolveu à margem do território cultural hegemônico igualmente dominado por tendências majoritárias da semiótica: a linhagem francesa e a americana. A trama de suas origens articula um cenário de outras dicotomias. O fato de emergir na Universidade de Tártu, Estônia, já é suficiente para revelar os contrapontos envolvidos: semiótica russa ou soviética? Cibernética da guerra fria ou ciência da informação? Transmissão ou controle? Para um dos proponentes do grupo, o professor de literatura Lótman, a semiótica da cultura deveria ser uma forma de enfrentar as próprias contradições de seu entorno e assumir o desafio de constituir e edificar sua metalinguagem crítica atacando a raiz do problema da dicotomia que lhe parecia residir na caracterização da tipologia da cultura.

No entendimento de Lótman,

[...] o estudo da tipologia da cultura supõe que se perceba como uma tarefa especial a elaboração de uma metalinguagem tal que satisfaça as exigências da atual teoria da ciência, quer dizer, que dê a possibilidade de tornar objeto de exame científico não só tal ou qual cultura, como também tal e qual método de descrição da mesma, havendo distinguido isso como uma tarefa independente (Lótman, 1998b, p. 96).

Em estudos em que explicita a necessidade entender os processos da interação entre sistemas de cultura e entre culturas segundo as relações tipológicas e topológicas, Lótman desenvolve um raciocínio crítico cujo objetivo é superar dicotomias. Ao questionar a legitimidade do processo de ocidentalização do planeta a partir do domínio da Europa central, jogando para a periferia todas as demais culturas e continentes, põe em dúvida o campo de forças que edificou o conceito de civilização como a identidade da cultura a partir do qual todas as demais culturas do planeta pudessem ser definidas de uma vez por todas. O alvo de Lótman, porém, é atingir uma estrutura consagrada, responsável pela mais perversa das dicotomias: aquela que opõe natureza e cultura e se torna referência para a constituição de todas as demais oposições. 
Ao adentrar nesse campo, Lótman e seus companheiros não estavam sozinhos. Trilhavam o caminho que Jakob von Uexküll desbravara ao fundar o campo de pesquisa sobre a diversidade do processo de significação construído por seres vivos e concebido em seus estudos como Umwelt ${ }^{1}$ (Uexküll, 2001; 2010).

O objetivo do presente artigo é compreender as bases conceituais do método semiótico desenvolvido pela metalinguagem crítica formulada por Lótman para fazer frente à mentalidade dicotômica tão fortemente constituída e instituída na cultura. Para isso, seguiremos os passos da análise comparativa que distingue o sutil movimento das transformações no interior dos diversos sistemas culturais, bem como das invariâncias estruturais nos regimes de mudanças. Quer dizer: ainda que tipologicamente as culturas preservem distinções, de um ponto de vista topológico se manifestam articulações sistêmicas que não podem ser simplesmente ignoradas sem o risco de eliminar a dinâmica de seu funcionamento enquanto tal.

\section{Por uma metalinguagem crítica da cultura}

No artigo denominado "Sobre a metalinguagem das descrições tipológicas da cultura" (1969), Lótman discorre sobre seu método em nome de uma recusa do modus operandi dominante que elegeu a dicotomia como procedimento inconteste para o estudo das culturas. O ponto central de sua refutação é a noção que confere privilégios a uma cultura que se auto-elege como «própria»e, por conseguinte, imbuída de autoridade para desenvolver mecanismos pelos quais as culturas "alheias" possam ser examinadas (Lótman, 1998b, p. 93-123), tal como no legado inconteste do etnocentrismo europeu, berço das demais dicotomias baseadas em polarizações responsáveis tanto pelas dominantes culturais quanto pelos confrontos geopolíticos. Civilização vs. barbárie; progresso vs. estagnação; culto vs. inculto; centro vs. periferia; cultura vs. não-cultura - eis alguns dos pares dicotômicos examinados por Lótman. Todos eles têm em comum uma controvérsia maior: a oposição entre natureza e cultura, sustentáculo do edifício antropocêntrico que consagrou a centralidade e superioridade da espécie humana no mundo dos seres vivos, eliminando

1 Em sua pesquisa desenvolvida na Universidade de Dorpat, atual Tártu, Uexküll observou como diferentes criaturas vivas do mundo, mesmo partilhando o mesmo habitat, constroem sentidos distintos sobre seu entorno. Ao transformar estímulos em propriedades, criam aquilo que constitui o automundo da espécie. Uexküll denominou este auto-mundo sensorial e subjetivo de Umwelt da espécie. Die Umwelt é, assim, um conceito cultural para a inter-relação entre percepção «do» mundo e operação «no» mundo desenvolvidas pelas espécies em seu habitat específico. (Uexküll, 2001, p. 108). 
qualquer possibilidade de dimensionar processos significantes para fora do ambiente humano e, portanto, dentro da Umwelt de cada espécie.

Contra tal abordagem, Lótman formula sua metalinguagem crítica comparativa onde «metalinguagem» surge como referência à capacidade inferencial de observação e análise das próprias estruturas significantes bem como de seu alcance em sua capacidade de significar o mundo, independente de máximas dedutivas ou exercícios de aplicação de teorias comprovadoras de conceitos. Se a metalinguagem aponta para o imprevisível das relações, assim também deveserentendidoomovimento críticoqueseconstituiemseunome.Em última análise, a metalinguagem crítica se volta para o entendimento do espaço semiótico onde relações de irregularidades, assimetrias, heterogeneidades simplesmente acontecem. Para isso, Lótman entende ser necessário contar com ferramentas conceituais diferenciadas e voltadas para o dimensionamento das capacidades geradoras de modelos de mundo traduzidos em diferentes formas de desenvolvimento cultural.

Observa que, em um espaço cujas articulações ocorrem em função das interações dialógicas, e não do domínio, o campo de forças se mostra muito mais propenso a se nutrir de mecanismos de ações complementares, ainda que reativas. Em vez de auto-eleição o que se observa é a prevalência da auto-regulação de modelos graças à ação de uma «memória informacional» em que a variedade e diversidade de processos culturais revelam-se dotadas de propriedades estruturais que se manifestam quando projetadas em perspectivas espaço-temporais de grande escala. Há aqui uma noção que merece esclarecimento.

"Memória informacional" diz respeito à informação culturalizada, isto é, informação que circula no fluxo das relações de seres que habitam o mundo em diferentes contextos espaço-temporais de sua Umwelt. Por conseguinte, inclui em seu horizonte o fluxo da "vida que gera vida" (na linha do que estudara Vladimir Vernadsky, 1997) graças ao qual é possível reconhecer um núcleo estrutural topológico que, na ação de mecanismos de transformação, preserva constituintes que nos permite falar em universais da cultura ou mesmo em culturalização - que não deve ser entendido como oposição à natureza. Pelo contrário, a memória informacional dimensionada como manifestação de espaço-tempo se apresenta, sobretudo, como estrutura cultural. Nesse sentido, nem mesmo os tão consagrados encontros culturais que identificam as imposições de uma cultura sobre a outra, gerando as dicotomias entre o "próprio" como dispositivo de submissão da cultura "alheia" e criando a condição do "estrangeiro", se mostram imunes às inflexões da análise comparativa. 
Uma compreensão reveladora da memória informacional no sentido gerador encontramos muito propriamente desenvolvida numa obra fílmica, o documentário do cineasta chileno Patricio Guzmán, sugestivamente intitulado Nostagia da luz ${ }^{2}$. Nele o potencial metalinguístico da luz como dispositivo estruturante da Umwelt da cultura humana é explorado às últimas consequências. Com isso, a grande dicotomia entre natureza e cultura é confrontada na raiz do processo gerativos, vale dizer, na natureza da luz a partir da qual as temáticas do filme são problematizadas. Para isso, Guzmán (2010) opera com uma metáfora conceitual que se tornou emblemática dos problemas políticos, culturais, científicos e humanos discutidos: a metáfora da memória como "força gravitacional". É no estudo dessa metáfora que vamos desvendando os caminhos da memória informacional de que tratava Lótman. O filme não se presta a um estudo de caso pois tampouco se presta a demonstrações de pressupostos prévios. Contudo, no jogo de suas hipóteses e inferências traça caminhos e diagramas de pensamento que se colocam como grandes desafios para a continuidade das reflexões.

Ainda que, num nível elementar, o documentário se preste ao uso da memória como ferramenta para revisitar o passado de modo a entender o presente e criar condições de projetar o futuro, a noção de força gravitacional cria um eixo de relações topológicas que nos aproxima do campo de constituição da memória informacional onde a "nostalgia da luz" aparece como a força de articulação entre a memória humana, da cultura e do universo. Com isso, o documentário de Guzmán firma o espaço traduzido em luz como matéria fílmica fundamental. Não apenas os telescópicos, como também a câmera cinematográfica, registram os fenômenos da luz e os projetam, conjugando a dimensão do espaço-tempo (Bowler e Mukherjee, 2011) como instância epistemológica do debate desenvolvido no filme. Assim focalizado, o filme situa um horizonte de análise que representa uma alternativa em que a metalinguagem crítica permite a elaboração de inferências que se colocam como alternativas aos edifícios teóricos solidamente consagrados. Além disso, a luz estruturada como matéria de espaço-tempo graças à mediação dos equipamentos técnicos criados culturalmente demanda uma compreensão como aquele dedicado a estruturas de grande complexidade como se espera elucidar na sequência. Para isso a metalinguagem crítica coloca em ação seus estudos sobre topologia.

2 Título: Nostalgie de la Lumière, Alemanha - Chile- Espanha - França. Direção: Patricio Guzmán, 2010. Documentário. Duração 90 minutos. 


\section{O deserto na mira do corte sincrônico de diferentes temporalidades}

Em uma das sequências iniciais do documentário Nostalgia da luz, uma imagem de satélite focaliza uma porção marrom do espaço geográfico.

\section{- Figura. 1: Deserto do Atacama em imagem de satélite reproduzida no filme}

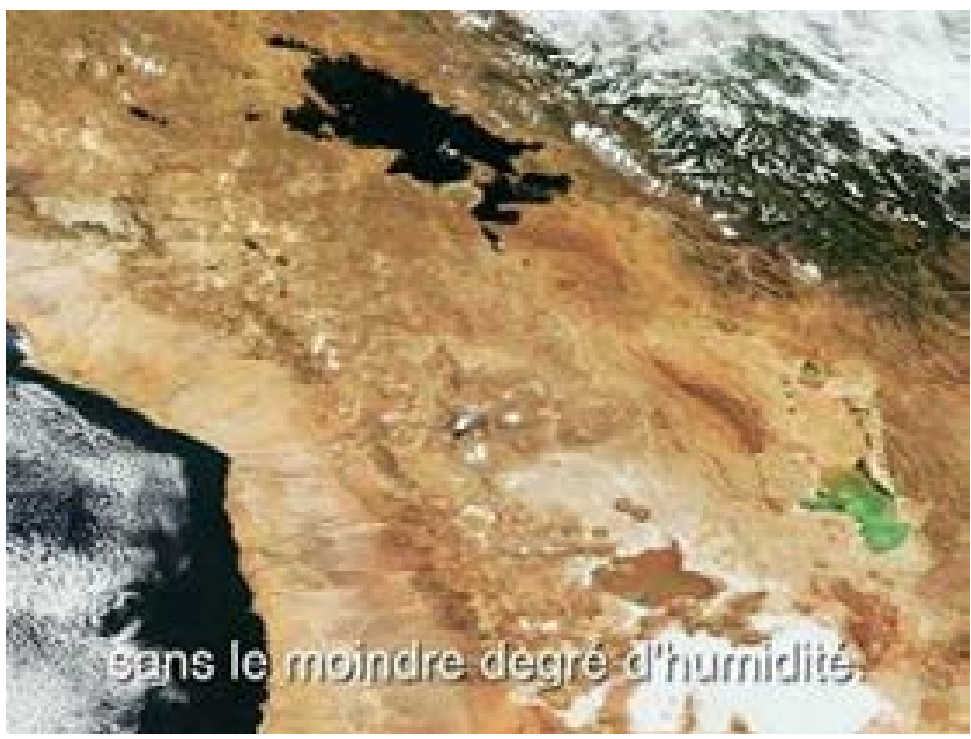

Fonte: Guzmán (2010)

Pelo recurso da voz-off de Guzmán, ouvimos:

Nosso planeta úmido tem uma única mancha marrom onde não existe nenhum grau de umidade. É o imenso deserto de Atacama. Imagino que o homem alcançará o planeta Marte em breve. O solo que tenho abaixo de meus pés é o mais parecido a esse mundo distante. Não há nada, não há insetos, não há animais, não há pássaros. Não obstante, está cheio de história (Guzmán, 2010, 8'24"- 9'17").

Quando, na sequência de seu movimento, a câmera se encontra com os telescópios e as imagens projetadas mostram uma atmosfera translúcida, privilegiada, que atrai astrônomos de todas as partes do mundo para investigar as estrelas cuja luz permite quase um contato com a mão, somos introduzidos num dos primeiros paradoxos do qual o documentário se alimenta. As imagens dos mais modernos telescópios do mundo, cravados no mesmo solo do deserto, bem como a riqueza das constelações estelares próximas e distantes apreendidas por suas lentes sofisticadas, se choca com a imagem da terra inóspita, hostil e estéril.

3 Os trechos enunciados em espanhol foram traduzidos livremente para o português. 
Se num plano imediato a metáfora do deserto se complexifica e se revela enigmática, em outro, o próprio relato de Guzmán pontua como aquele espaço desértico conjuga a relação de ciência e política. No auge do governo de Salvador Allende, a cibernética se tornou chave de um conhecimento em prol da implantação de reformas sociais de grande alcance (Rivière, 2010). Ciências de diferentes campos do conhecimento desfrutaram de prestígio e livre desenvolvimento (Maturana, 1997). Logo, não é de se estranhar que o esplendor e a derrocada articulem os discursos e a metáfora do deserto no filme.

Da curvatura dessas duas matrizes espaciais - o céu translúcido e a terra estéril - se projeta a variedade espaço-temporal do documentário e o deserto começa a ser explorado na rica trama de sua memória. Como afirma Guzmán (2010, 10'20"), "o ar transparente e luminoso nos permite ler o grande livro aberto da memória, página por página".

Apesar dos confrontos da relação assimétrica, que a abordagem tipológica nos obriga a manter no plano da intraduzibilidade, diferentes leituras são apresentadas no documentário, e todas buscam pelo mesmo fenômeno: as informações do passado dispostas em camadas ou em páginas, como se referiu Guzmán, a guardá-lo sob diferentes códigos, como se esclarece no fragmento.

Como outros desertos do planeta, o deserto chileno é um oceano de minerais enterrados. A céu aberto, estão os homens que morreram trabalhando. Como as camadas geológicas, há camadas de mineiros e de indígenas que movem o vento que nunca cessa. Eram famílias errantes. Seus pertences e suas recordações estão próximas dali (Guzmán, 2010, 27'37"- 28'30").

A sequência fílmica que acolhe esse enunciado se inicia com as cruzes e restos petrificados de objetos silenciosos e se funde a uma sequência sonora de vento e de colheres a tilintar numa habitação abandonada, numa autêntica instalação sonora de metais e sopros de vento. O silêncio do cemitério e a ruidosa paisagem dos pertences colocam a memória informacional em movimento. 
- Figura. 2: Cemitério a céu aberto no deserto de Atacama, em sequência do filme

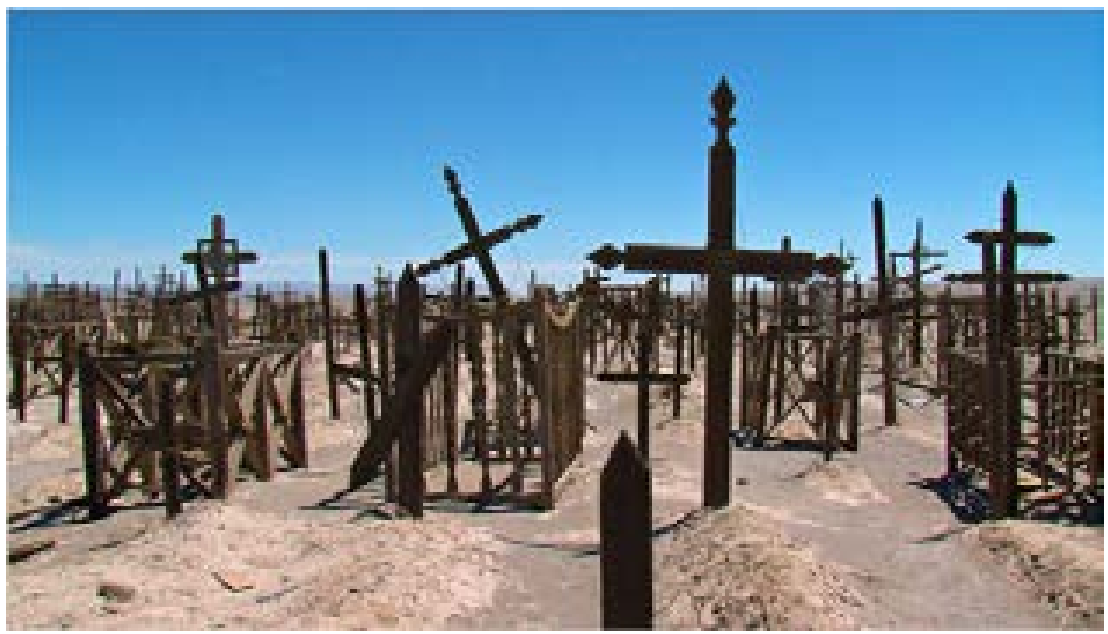

Fonte: Guzmán (2010)

Enquanto o cientista aponta o telescópio para o céu, o cineasta aponta sua câmera para o deserto em busca das camadas de diferentes temporalidades. Assim como o solo dispõe os estratos de informação do passado, os espaços também se valem do mesmo processo. Rios de pedras indicam o caminho de ligação do altiplano ao mar; inscrições em rochas tornam presente o período pré-colombiano; vestígios e ossadas evidenciam a movimentação dos povos nômades. Sobre esse estrato, se erguem as ruínas das atividades de mineração do século 19, que fizeram do salitre produto da riqueza econômica sustentada pela exploração de mão de obra escrava. Nos anos da ditadura do general Augusto Pinochet, tais ruínas serviram de campo de concentração para o confinamento de presos políticos. E os condenados desenhavam os caminhos da liberdade construindo cartografias das constelações estelares.

Com isso, o solo do deserto guarda camadas de vidas que colocam nômades, escravos e presos políticos num mesmo patamar de privações. Por meio delas, o tempo é espacializado criando uma hierarquia complexa de códigos que a memória informacional acumula e que o documentário tenta reorganizar.

O deserto abre, nas páginas de sua memória, muitas portas para o passado e o tempo supostamente congelado coexiste com o tempo em movimento o que imprime uma certa porosidade ao espaço do suposto tempo presente. Ampliam-se os canais de trânsito e de busca. Assim, arqueólogos interessados nos vestígios de civilizações se unem aos astrônomos que examinam os corpos celestes e ambos fazem do deserto um espaço de pesquisa e conhecimento histórico. Nos últimos 20 anos, um outro conjunto de pessoas se voltou para 
o deserto como espaço de busca. Trata-se da comunidade das mulheres que, privadas de seus familiares, desaparecidos políticos durante a ditadura, encontraram um fio de esperança ao vasculhar o terreno do deserto em busca dos corpos que faltam.

Ao situar o deserto como depósito de restos mortais do universo e dos seres vivos que lá pereceram, ganha vigor a hipótese de que o deserto no documentário concentra diferentes buscas pela informação do passado que, por sua vez, se orienta pela memória informacional construída em camadas. As mulheres que escavam o deserto há mais de duas décadas descobriram pequenos ossos humanos calcificados. Para os arqueólogos, tal descoberta é reveladora do modo como os mortos da ditadura foram enterrados e depois retirados com o auxílio de máquinas e tratores para serem transportados e lançados ao mar. A análise dos fragmentos ósseos levou os astrônomos à descoberta da linha do cálcio encontrada na calcificação das estrelas. Segundo o depoimento de George Prestom: “O cálcio nos meus ossos está lá desde o começo" (In: Guzmán, 2010, 1h08'20").

Contudo, segundo a voz off de Guzmán,

\begin{abstract}
a busca das mulheres nunca se cruzou com a busca dos astrônomos que rastreavam outro tipo de corpos, os corpos celestes. Enquanto as mulheres tocavam a matéria do deserto, os astrônomos detectaram que a matéria da terra era a mesma em todas as partes do cosmos (Guzmán, 2010, 1h12'18").
\end{abstract}

No entanto, a busca pelo passado constrói a topologia que articula os diferentes rastreamentos ao mesmo tempo em que situa natureza e cultura num único alinhamento desenhado pela memória informacional com a qual interagimos graças ao cinema. Do ponto de vista da memória informacional, os corpos calcificados das ossadas, os corpos luminosos estelares e o corpo-luz fílmico se situam na mesma frequência: aquela da especulação sobre as origens de corpos, do universo e da luz. Daí a inferência segundo a qual sistemas culturais tão distantes passam a operar numa região topológica de proximidade em que a memória desempenha a função de eixo organizador.

\title{
Memória como força gravitacional topológica
}

Ainda que se coloque como desafio, a metáfora conceitual formulada por Guzmán atribui à memória o poder de organização graças à força gravitacional de que se investe. Assim como a gravidade que impulsiona a matéria e os corpos onde quer que ela se manifeste, Guzmán acredita que a memória esteja 
integrada ao movimento que se manifesta nos astros, nos objetos, nas pessoas, nos países. Segundo o cineasta, nós somos "atraídos pela memória", e essa é a condição indispensável para se viver na efemeridade que é a vida dos seres vivos.

Não precisamos de muitos conhecimentos de física ou de astronomia para trabalhar com a metáfora conceitual de Guzmán. Se por força gravitacional se entende a lei de atração e a constância de um movimento orbital, não é difícil entender que nela atua a continuidade do movimento uma vez que tudo se desloca em sua direção. De onde se infere que a inércia não é condição do estado da matéria.

Quando se identifica na memória uma força gravitacional a garantir o movimento dos eventos, das pessoas e de todas as coisas, a memória não se mostra nem como lugar nem como pertencimento de uma classe de seres e de objetos, mas se constitui como dispositivo elementar de tudo o que está vivo e, portanto, em movimento. Estamos, pois, frente a um dispositivo topológico e não frente a uma propriedade.

No documentário tal movimento topológico se configura nos dois eixos temáticos da exposição: a pesquisa científica de astrônomos e arqueólogos e a busca de mulheres pelos resíduos ósseos nos arredores. Em ambos os casos a força gravitacional empurra as investidas para a luz como impulso do deslocamento rumo ao passado. Para os astrônomos, a exuberância e transparência da luz esconde os mistérios das origens; para as mulheres, a ausência da luz esconde o afastamento de seus entes queridos que se traduz na perda do convívio que relega os corpos à vivência das trevas nas entranhas da terra.

Com base nessas premissas, o filme nos coloca diante de uma outra hipótese, tão ousada quanto as anteriores: nossas origens, nossas raízes, podem estar na luz e não no Sol, como infere Guzmán.

Alguém me disse que há meteoritos abaixo das rochas que alteram as bússolas. Sempre se acreditou que nossas origens se encontravam no sol enterrado debaixo da terra ou ao fundo do mar. Mas agora penso que nossas raízes podem estar acima, mais além da luz (Guzmán, 2010, 13'09"- 13'-34").

E dessa hipótese se desdobra o diagrama argumentativo que une, topologicamente, a relação entre o passado e o presente; a pesquisa científica e a busca das mulheres; o telescópio e o cinema; a percepção do mundo e as coisas existentes; a força gravitacional e a nostalgia. Comecemos pela noção de tempo presente não como oposição ao passado, mas como fluido. 
Desde o início, o documentário insiste na noção de presente como "o único tempo que existe" (Guzmán, 2010, 5'47"). Assim o cineasta se refere ao tempo de sua infância e ao tempo do governo de Salvador Allende, onde a ciência e a cibernética conheceram seu momento de esplendor.

Galaz, um dos astrônomos entrevistado pelo documentarista, segue uma outra linha de raciocínio e afirma que o presente simplesmente não existe. $O$ que existe é a luz daí a necessidade de persegui-la, estudá-la, conhecê-la. Do ponto de vista da luz, o presente não existe enquanto ação distintiva, mas tão somente como processo relacional. Explica-se tal formulação considerando-se o descompasso e assincronia entre as imagens do mundo e o momento em que nossa percepção sobre elas se manifesta. Olhando diretamente para a câmera, Galaz nos diz:

Toda a experiência que temos da realidade, como essa conversa, teve lugar num passado distante por um milionésimo de segundo. A câmera que eu olho agora se encontra há alguns metros de distância, portanto, há alguns milionésimos de tempo atrás, num passado em relação ao tempo que tenho no meu relógio. Porque o sinal demora a chegar, a luz da câmera demora a chegar até mim numa fração de segundos muito pequena, porque a velocidade da luz é muito rápida. Nada se vê no instante em que se vê (Guzmán, 2010, 17'36"- 18'23").

A ínfima porção de segundo que a luz gasta para atravessar o espaço e chegar até nós é suficiente para assegurar a não sincronia entre o momento em que se fixa o olhar sobre os objetos e a percepção. Por conseguinte, a informação do passado também se situa num mesmo nível de temporalidade, o que reforça a ideia de sobreposição de temporalidades na busca, seja do astrônomo, do arqueólogo ou das mulheres, que vivem em estado de busca e controlado pelo passado. Tudo isso é o que faz do deserto com suas fontes de luz de um céu transparente o espelho da própria memória informacional para a qual se veem atraídos em sua busca pela origem da vida. Ciência, religião e indivíduos - Todos movidos pela mesma força gravitacional.

Tal é o que se apreende na esfera das evidências e dos discursos enunciados. Todavia algo de novo emerge quando a busca é situada no contexto da memória informacional traduzida na frase título do filme: «nostalgia da luz» - que parece sustentar a própria origem e preservação da força gravitacional.

Antes de avançarmos na análise de nossa hipótese, há que se considerar alguns pressupostos já consensuados. Trata-se da compreensão da noção de nostalgia como conceito político que tem sido redimensionada no contexto da diáspora e das ditaduras latino-americanas do século 20 , onde o cinema de 
Guzmán se projeta como cinema de exilado. Segundo a chave conceitual da diáspora, nostalgia traduz tanto o exílio, quanto a metáfora do eterno retorno de Ulisses em sua odisseia pelos mares de sua peregrinação (Vitullo, 2013, p. 186). Segundo Vitullo, a trama nostálgica se mostra mobilizadora pela capacidade de "temporizar o espaço" e "espacializar o tempo" de modo a projetar o futuro - o que se torna um caminho favorável a interpretar a nostalgia de Guzmán no âmbito de sua ferida mais funda, cravada pelo regime da ditadura militar (Vitullo, 2013, p. 187).

Não se trata de refutar aqui a coerente inserção do documentário no contexto do cinema da diáspora, mas de avançar na trama interpretativa a partir do título do documentário inspirado pelo título do livro do astrofísico e poeta francês Michel Cassé, Nostalgie de la lumière: Monts et ferveilles de l'astrophysique (1987). Nele, o entendimento da memória como força gravitacional é mediada pela metáfora da nostalgia da luz. Segundo Cassé, entende-se por força não somente aquilo que intensifica, empurra ou modifica o movimento, mas também tudo o que incita a mudança e a metamorfose. Com isso, força se torna interação e o único agente possível de transformação. A gravitação é a força dominante na escala cósmica uma vez que ela é infinita e não contracena com nenhuma força antigravitacional. Não se pode afirmar o mesmo sobre a força eletromagnética que, embora dotada de alcance ilimitado, não pode governar o vasto cosmos em estruturas maiores, porque as cargas elétricas positivas e negativas em igual número tendem a se neutralizar ${ }^{4}$. Donde podemos inferir que nostalgia diz respeito a essa força que, embora presente, pode ser ausente, neutralizada.

Num dos depoimentos carregados de emoção, Berrios afirma que ela não desiste de buscar pelo corpo de Mário e que a grande efeméride de sua vida seria o dia em que ela pudesse encontrar o corpo de seu Mário inteiro. Sua obstinação é tão forte quanto a esperança que alimenta seu sonho. E ela não hesita em confessar: "Eu gostaria que os telescópios não mirassem só o céu, mas que eles pudessem transpassar a terra para poder buscar...É um sonho" (In: Guzmán, 2010, 1h 03'17").

Ao relacionar o sonho de Berrios ao entendimento de Galaz sobre o tempo presente como fenômeno da luz temos um jogo metalinguístico do próprio

$4 \quad$ O trecho referente ao estudo de Michel Cassé foi adaptado de um trecho de seu livro publicado em Activité documentaire sur un texte de Michel Cassé. Disponível em: <http://pardailhan.entmip.fr/... reFichiergw.do?ID_FICHIER=... >. Acesso em: 7 jul. 2015. 
- Figura. 3: Plano de Julieta Berrios em tomada do filme

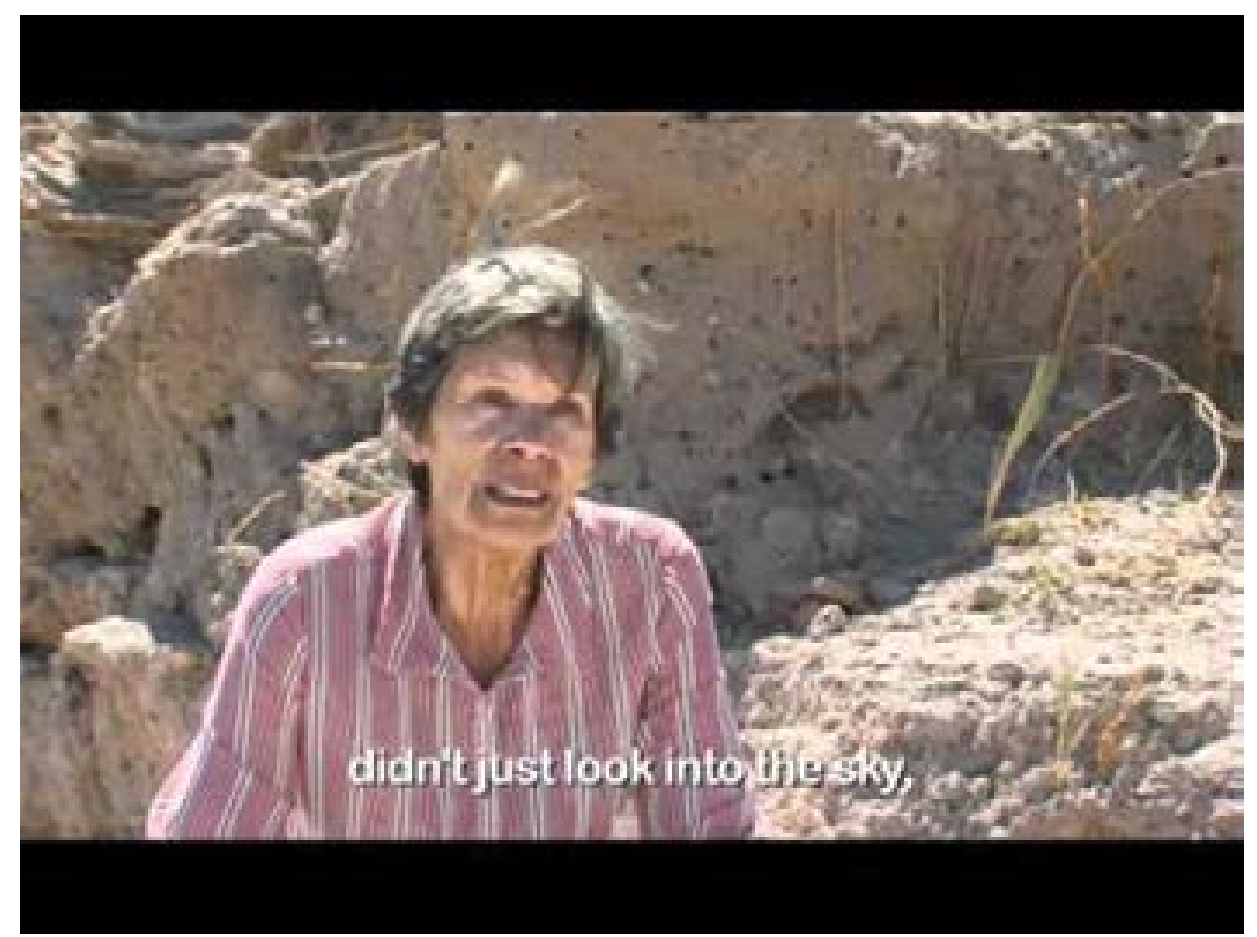

Disponível em: <http://i.ytimg.com/vi/7FvhsYCkcN8/hqdefault.jpg>. Acesso em: 7 set. 2015.

cinema que organiza todas essas informações como memória viva. Para nossa surpresa, na sequência é introduzido um outro projeto científico destinado a construir sonares capazes de capturar ondas sonoras e alcançar a luz, mesmo aquela escondida nas estranhas da terra, como se pode ouvir/ler no relato de Guzmán:

Há 5.000m de altitude o radiotelescópio ALMA está sendo construído graças a um financiamento internacional. Comportará 60 antenas quer dizer 60 orelhas para escutar as ondas do céu. Poderá escutar as ondas dos corpos cuja luz não chega à Terra; registrará a energia que se produz no Big Bang (Guzmán, 2010, 43'27"- 43'57").

Ao se inteirar das pesquisas dos astrônomos e geólogos, Berrio suscita a hipótese de os sonares dirigirem suas ondas de luz para o solo de modo a vasculhar as entranhas da terra, enchê-las de luz e revelar os corpos que tanto buscam. A força de seu clamor reside em sua compreensão dos corpos vivos como corpos de luz que, enterrados, foram neutralizados nessa condição. A tenacidade de sua busca é apenas e tão-somente a forma de restituir a magnitude dos seres de luz, inclusive de seu Mário. Consciente ou inconscientemente ela 
nos ensina um dos sentidos mais fundos da palavra nostalgia, o sentido poético que não estava fora do campo semântico de Cassé.

Etimologicamente nostalgia é um termo formado do grego nóstos (reencontro) e álgos (dor, sofrimento) - que pode ser entendido como uma doença do espírito. Nostalgia da luz pode ser uma doença dos corpos carentes de luz, o que é válido tanto para os corpos celestes quanto para os terrestres. Contudo, nostalgia indicia também o reencontro da luz, como sustenta um dos astrônomos que fala no documentário. Nesse sentido, nem os astrônomos nem as mulheres buscariam pelos restos mortais, mas sim pelos rastros, vestígios e indícios da vida de pessoas e de seres que fazem parte de suas vidas e da história viva do universo.

A nostalgia da luz entende por seres vivos tanto as pessoas que buscam pelos corpos de pessoas, quanto as pessoas que buscam pelos corpos celestes. Todos estão a buscar uma informação sob forma de alguma energia viva, a vida que gera vida - endossando a máxima de Vernádski-Lótman (Lótman, 1990), no caso a luz-temporalidade que conjuga o presente e o passado.

A nostalgia da luz corresponderia, assim, a um impulso - força gravitacional - que busca pelo começo, pelos indícios da vida expandida numa escala cada vez maior de vida. Nesse sentido, a concepção de nostalgia da luz ressoa no surpreendente conceito de autopoiesis do outro chileno, o biólogo, Humberto Maturana, que segue na mesma linha de pensamento: a vida que gera vida e se autoreferência ${ }^{5}$ (Varela, 2000, p. 419-451).

Nenhuma dessas aproximações, contudo, seriam possíveis se fossem consideradas apenas as experiências que correm no plano empírico imediato. A nostalgia da luz tal como nos leva a entender a hipótese baseada no efeito de neutralização da força eletromagnética expresso por Cassé são de caráter topológico. Acontecem no plano das invariâncias sejam elas consideradas neutralização, carência, ausência. Essas são as constantes que reverberam no plano físico do deserto, no plano cósmico, no plano psíquico.

Se nossas raízes estão na luz, entendo que a metáfora da memória como força da gravidade e de geração de vida se coloca numa esfera de reflexão que me permite dimensionar, no filme de Guzmán, a autopoiesis da luz, sobretudo

5 Noção que emerge nos estudos de Humberto Maturana e Francisco Varela nos anos de 1970 no desenvolvimento de estudos sobre a autonomia da organização celular dos seres vivos. Autopoiesis (neologismo que se estende do termo grego poiesis) designa a auto-organização dos sistemas vivos em sua capacidade de auto-referencialidade como condição de permanência. 
porque a metáfora se materializa como projeção de luz num filme que se realiza na espacialidade da memória, aponta para os escombros e as entranhas, se não da terra, pelo menos de seres cuja luz se encontra esmaecida pela nostalgia. Nesse sentido, o próprio cineasta está inserido no filme e sua busca se constrói no documentário que elabora.

A frase final do filme, enunciada numa tela de pontos de luz da noite de Santiago do Chile não poderia ser mais contundente. Nela, Guzmán afirma:

Eu creio que a memória tem uma força de gravidade que sempre nos atrai. Os que tem memória são capazes de viver no frágil tempo presente; os que não tem não vivem em nenhuma parte (Guzmán, 2010, 1h 27'11"- 1h 27'29").

\section{Mecanismos inteligentes em ação nas transformações culturais}

Deserto e estrelas; telescópio e sonares; busca e sonho: eis os elementos que fazem de Nostalgia daluzum filmecujo espaçoéa luz-elemento estruturante da metalinguagem do cinema nesse espaço desenhado por grandes topologias, sem dicotomias. Voltemos a Lótman.

Quando envereda para a construção de uma metalinguagem para a descrição da cultura com base nos modelos espaciais topológicos, Lótman deixa claro que lhe interessa acompanhar as transformações culturais de estruturas que permanecem invariáveis num contexto de variações, ou seja, a memória informacional do sistema ou, simplesmente, sua topologia. Noção que ele elabora com base na "disciplina matemática [topologia] que estuda as propriedades das figuras que não mudam ante as transformações homeomorfas" (Lótman, 1998b, p. 97). Encontra nos códigos culturais - primeiro de línguas e depois das linguagens da cultura na sua diversidade - os exemplares fundadores desse entendimento topológico e da memória informacional dos sistemas que emergem, assim, de uma demanda interna da própria cultura: a co-evolução de linguagens discretas de signos verbais com as linguagens icônicas de signos gestuais e cinéticos do ambiente interativo, como se pode ler no trecho seguinte.

O traço mais universal do dualismo das culturas humanas é a coexistência de linguagens discretas verbais e linguagens icônicas em cujo sistema os diferentes signos não formam cadeias senão que se fazem em uma relação de homeomorfismo atuando como símbolos mutuamente semelhantes (cf. A ideia mitológica do homeomorfismo entre o corpo humano e as estruturas social e cósmica) (Lótman, 1998a, p. 28). 
Ainda que sejam reconhecidas as línguas e linguagens geopoliticamente dominantes - caso dos instrumentos técnicos como o telescópio, a câmera e os sonares - é impossível não dimensionar os códigos que constroem «estruturas de grande complexidade» (Lótman, 1979, p. 35) e desenham «hierarquias complexas» (Lótman, 1998a, p. 14) e não simplesmente hierarquias de valor. Por conseguinte, em encontros de grandes complexidades os agentes de atrito constroem zonas de intraduzibilidade, de resistência e de fronteiras em que a memória informacional faz valer a força de seus constituintes topológicos. Em Nostalgia da luz tais zonas são exploradas em seus grandes eixos temáticos de busca dos cientistas, das mulheres, do documentarista.

Qualquer estrutura de grande complexidade é dotada de dinâmicas de funcionamento em diferentes níveis. Tanto opera no nível de conservação dos códigos quanto na sua capacidade gerativa. $O$ dualismo de tal funcionamento sugere a Lótman a operação na cultura dos processos de inteligência a exemplo das ocorrências no cérebro do organismo humano. Afirma-se, por conseguinte, que a cultura é dotada de mecanismos operacionais de inteligência identificadas no funcionamento de sua memória informacional. Além de transformar as coisas do mundo em signos, a memória informacional preserva seus constituintes estruturais sendo capaz tanto de gerar novas informações quanto de lançar outras tantas no esquecimento. Como memória, a complexidade tipológica e topológica mostra-se capaz de sustentar a inteligência do sistema cultural. Vale lembrar, por conseguinte, que em nenhum momento a ação que conduz ao esquecimento deve ser entendida seja como ato de subjugamento ou de morte; pelo contrário, trata-se de um deslocamento para ulterior reintegração, ou melhor, trata-se de uma «nostalgia da luz».

Ainda que a inteligência humana tenha sido o ponto de partida para introduzir a memória da cultura como mecanismo operacional da tipologia e da topologia, é no qualificativo «informacional» que reside a chave para definir o conjunto das ações de preservação, disseminação, geração da memória da cultura em termos de funcionamentos que são da cultura e não do cérebro humano. É de informação que trata quando se projeta o movimento de transformação seja para alcançar-lhe os constituintes invariáveis, seja para acompanhar o caminho da transformação e da geração do novo.

E aqui vale situar não apenas o processo de codificação e do nascimento dos códigos a oferecer a informação semiotizada, como também a recodificação da informação que se transforma ao ser reconfigurada pela dinâmica cultural. Em diversos contextos culturais, tanto a recodificação quanto seus correlatos - a transcodificação, transmutação e transdução-se manifestam como mecanismos de reorganização do sistema e, portanto, de participação no processo de auto- 
regulação que lhe confere o estatuto operacional de mecanismo inteligente. É de transdução que se trata quando se opera topologicamente a sequência do sonho de Berrios, do sonar e da luz como movimento de espaço-tempo todos eles traduzidos em cinema: espaço-luz.

Tipologia e topologia só se tornam possíveis porque a comparação em vez de incentivar dicotomias e hierarquias, busca recompor o quadro das relações internas e externas sem as quais a cultura não seria um fenômeno plural desenvolvida no gradiente das manifestações da natureza. No artigo dos anos 60 , Lótman lança sementes de um pensamento semiótico que fez da noção de espaço semiótico o campo de estudo privilegiado dessas manifestações, base da concepção da semiosfera que se consolidaria quinze anos mais tarde.

\section{Considerações finais}

O conceito de nostalgia da luz projetado como a grande metáfora da interação entre presença e ausência, natureza e cultura, retoma o descompasso entre visão e percepção apresentado anteriormente. Nesse ponto o raciocínio do astrônomo sintetiza o grande paradoxo do cinema uma vez que aquilo que desfila numa tela diante de nossos olhos não deixa de reproduzir o ficou registrado enquanto traços de luz e não enquanto pessoas ou acontecimentos. O mesmo raciocínio reverbera nas imagens fotográficas que aparecem com a imagem das pessoas quase apagadas, sem luz, colocando em evidência aquilo que falta. Torna-se empenho, também, o cinema situar-se como máquina de recuperar o passado e construir com ele sua metalinguagem crítica de luta contra o esquecimento. Nesse sentido, o cinema se alia aos telescópios e sonares para compor a metalinguagem crítica do grande embate entre natureza e cultura seguindo os vieses da análise tipológica dos modelos de mundo que observa e mantém em suas zonas de resistência, intraduzibilidade, fronteira.

A nostalgia da luz, que conjuga uma tipologia de sistemas culturais e com eles articula uma topologia da memória informacional do passado espacializado em camadas de temporalidades, evidencia a ausência e a luta por trazer à luz tudo o que se encontra encoberto. O cinema no documentário funciona como uma espécie de sonar a empreender a sondagem de tudo que ficou encoberto no passado. Seu trunfo é o papel da memória como força gravitacional, cujo impulso é canalizado para a luta contra o esquecimento e como forma de sobrevivência. 


\section{Referências:}

BOWLER, Ryan; MUKHERJEE, Rahul. Documentary and Space: Introduction. Media Fields Journal. Critical Explorations in Media and Space, n. 3, p. 1-13, 2011. Disponível em: <http://www.mediafieldsjournal.org/introduction-issue-3/ PDF> Acesso em: 24 ago. 2015.

CASSÉ, Michel. Nostalgie de la lumiére: Monts et merveilles de l'astrophysique, 1987.Collection Belfond/Sciences, French Edition - França. 1987.

GUSMÁN, P. Nostalgie de la Lumière. Alemanha-Chile-Espanha-França. Direção: Patricio Guzmán, 2010. Documentário. Duração 90 minutos.

LÓTMAN, I.M. Sobre o problema da tipologia da cultura. In: Semiótica russa. B. Schnaiderman, org. São Paulo: Perspectiva, p. 31-41, 1979.

El fenômeno de la cultura. In: La Semiosfera. Semiótica de la cultura, del texto, de la conducta y del espacio. D. Navarro, org. Madrid: Cátedra, p. 2541,1998a.

. Sobre el metalenguaje de las descripciones tipológicas de la cultura. In: La Semiosfera. Semiótica de la cultura, del texto, de la conducta y del espacio. D. Navarro, org. Madrid: Cátedra, p. 93-123, 1998 b.

MATURANA, Humberto. Emociones y linguaje en educación y política. Santiago: Dolmen, 1997.

RIVIÈRE, Philip. O governo cibernético de Salvador Allende. Le monde diplomatique, 1 de julho de 2010. Disponível em: <http://www.diplomatique.org.br/artigo. php?id=736>. Acesso em: 8 set. 2015.

UEXKÜLL, Jakob von. An Introduction to Umwelt. Semiotica, n. 134, p. 107-110, 2001. . Milieu animal et milieu humain. Paris: Payot \& Rivages, p. 174, 2010.

VARELA, Francisco. Retro-perspectiva: origenes de una idea. El fenómeno da vida. Santiago: Comunicaciones Noroeste, p. 419-451, 2000.

VITULLO, J. Nostalgia de la luz de Patricio Guzmán: El cine como máquina del tiempo. Kamchatka. Revista de Analisis Cultural, $n^{\circ}$ 2, p. 179-192, 2013. Disponível em: <https://ojs.uv.es/index.php/kamchatka>. PDF. Acesso em: 7 jul. 2015. 